\title{
Vencimentos dos professores das redes municipais das mesorregiões Sudeste e Centro-Oriental do Paraná
}

\author{
Salary of teachers of the municipal networks of the Southeastern and Central- \\ Eastern mesorregions of Paraná \\ Vencimientos de los profesores de las redes municipales de las mesorregiones \\ Sudeste y Centro Oriental de Paraná \\ MICHELLE FERNANDES LIMA \\ GISELE MASSON \\ ARTUR LOURIVAL DA FONSECA MACHADO
}

\begin{abstract}
Resumo: Em pesquisa de pós-doutoramento analisamos vencimentos iniciais e finais de professores das redes municipais de 35 municípios, problematizando diferenças salariais face a dados que caracterizam o desenvolvimento econômico e social. A pesquisa das leis dos planos de carreira e das tabelas salariais evidenciou que, além do desenvolvimento econômico e social, há outros elementos que interferem na valorização do professor, entre eles o interesse político do gestor municipal.
\end{abstract}

Palavras-chave: valorização docente; vencimento; planos de carreira; redes municipais de educação.

\begin{abstract}
In the post-doctorate research we analyzed initial and final earnings of municipal teachers of 35 municipal districts, questioning earning differences face to data that characterize the economic and social development. The understanding of the laws of the career plans and of the earning tables evidences that there are, beyond economic and social development, other elements that interfere in the teacher's valorization, among them the political interest of the municipal manager.
\end{abstract}

Keywords: teacher valorization; earnings; career plans; municipal education network.

Resumen: En la pesquisa de post doctoramiento analizamos vencimientos iniciales y finales de maestros de las redes municipales de 35 municipios, cuestionando las diferencias de sueldos frente a datos que caracterizan el desarrollo económico y social. La investigación de las leyes de los planes de carrera y de las tablas de sueldos evidenció que, además del desarrollo económico y social, hay otros elementos que interfieren en la valoración del maestro, entre ellos el interés político del gestor municipal.

Palabras clave: valoración docente; vencimiento; planes de carrera; redes municipales de educación. 


\section{INTRODUÇÃO}

A valorização docente é um tema complexo e abrangente, em que três principais elementos podem ser investigados: condições de trabalho, remuneração, formação inicial e formação e continuada.

$\mathrm{O}$ vencimento dos professores pode ser entendido como um elemento de destaque a ser investigado, pois, como afirma Masson (2016, p. 158)1: "é um fator decisivo para a permanência no magistério, uma vez que a garantia da existência humana depende, em primeira instância, do acesso aos bens necessários à satisfação das necessidades históricas, o que depende essencialmente de um salário compatível."

Essa afirmação indica a necessidade de estudos que contemplem a diversidade de planos de carreira nas redes estaduais e municipais, para verificar de que maneira estão organizados, apontando diferenças e os inúmeros desafios para a garantia de condições necessárias para a atratividade na carreira docente.

Grande parte das investigações sobre a valorização docente na Educação Básica contempla os estados e capitais, o que oferece um conjunto de dados e análises sobre as diferenças de carreira no país; no entanto, consideramos importante contribuir para esse debate a partir de investigação da carreira docente das redes municipais.

As investigações sobre valorização docente podem versar sobre os três elementos essenciais (remuneração, condições de trabalho e formação continuada) e, no caso específico dessa pesquisa, tratamos do elemento "vencimento" dos professores das redes municipais de 35 municípios das Regiões Sudeste e CentroOriental do Paraná, a partir da caracterização dos planos de carreira, tendo como base os documentos disponíveis nas páginas institucionais. Para uma melhor compreensão da conceituação referente à valorização docente, destacamos a diferenciação de alguns termos, a partir da contribuição de Camargo et al. (2009, p. 342, grifo nosso):

O salário é definido juridicamente como uma retribuição paga diretamente pelo empregador ao empregado pelo tempo de trabalho realizado. Assim, só o montante pago pelo empregador a título de retribuição é considerado "salário" - nos termos da Consolidação das Leis do Trabalho (CLT). Já o termo "vencimento" é definido legalmente (Lei n. 8.112, de 11/12/1990, art. 40) como "retribuição pecuniária pelo exercício de cargo público, com valor fixado em lei". Os vencimentos dos cargos efetivos são irredutíveis e, para cargos de mesma atribuição ou de atribuição 
semelhante na mesma esfera administrativa, é garantida isonomia. O conceito de "remuneração", por sua vez, pode ser definido como o montante de dinheiro e/ ou bens pagos pelo serviço prestado, incluindo valores pagos por terceiros. A remuneração é a soma dos benefícios financeiros, dentre eles o salário, acordada por um contrato assinado entre empregado e empregador. O salário é, assim, uma parte da remuneração.

O Art. 37 da Constituição Federal define cargo público, pautandose pelos princípios da legalidade, impessoalidade, moralidade, publicidade e eficiência, bem como pela regra de acesso ao cargo público pela via do concurso, aliado à irredutibilidade de vencimentos e estabilidade funcional. A Lei ${ }^{\circ}$ 8.112, de 1990 (BRASIL, 1990), regulamenta o Regime Jurídico dos Servidores Públicos do Brasil, para o vínculo jurídico que liga os servidores públicos da administração direta (ministérios, órgãos e poderes) e da administração indireta (autarquias e fundações públicas federais) com a administração pública federal. Os servidores das esferas distrital, estaduais e municipais possuem um estatuto próprio que, pelo princípio da conformidade, é definido pelo ordenamento constitucional e se adéqua à Lei no 8.112/90 (BRASIL, 1990).

Tratando-se de planos de carreira do magistério das redes municipais, os municípios possuem estatutos próprios para os servidores públicos elaborados à luz dos ordenamentos jurídicos previstos no Regime Jurídico dos Servidores Públicos, com base na Lei no 8.112/1990 (BRASIL, 1990). Nessa legislação, é estabelecido o regime estatutário, que possui regras diferentes do regime celetista. Denomina-se "estatutário" porque os deveres e obrigações derivam de dispositivos do estatuto legal, ou seja, lei específica que regulamenta a relação entre as partes, possuindo natureza de direito administrativo.

Observadas essas questões referentes ao regime jurídico dos servidores públicos, é importante conceituar remuneração como aquela constituída pelos vencimentos do cargo, mais vantagens pecuniárias permanentes ou não, definidas em lei. No magistério, a legislação define as bases para a carreira e o piso salarial a ser aplicado nos estados e municípios. O público contemplado nessa legislação são os profissionais do magistério público, entendidos como:

Aqueles que desempenham as atividades de docência ou as de suporte pedagógico à docência, isto é, direção ou administração, planejamento, inspeção, supervisão, orientação e coordenação educacionais, exercidas no âmbito das unidades escolares de educação básica, em suas diversas etapas e modalidades, com a formação mínima determinada pela legislação federal de diretrizes e bases da educação nacional. (BRASIL, 2008, Art. 2, inciso $2^{\circ}$ ). 
As garantias constitucionais e demais legislações e atos normativos, fruto de lutas do movimento docente, nem sempre são implementadas. Masson (2016) realizou estudo sobre a valorização dos professores da educação básica nos estados e explica que o cumprimento da lei do piso é um tema controverso. A autora destaca

A Ação Direta de Inconstitucionalidade (Adin $\mathrm{n}^{\circ}$ 4167), conduzida pelos governadores de Mato Grosso do Sul, Rio Grande do Sul, Paraná, Ceará e Santa Catarina, e com apoio posterior dos estados de Roraima, São Paulo, Tocantins, Minas Gerais e Distrito Federal. Em que pese o fato de a Adin ter sido julgada improcedente, ainda há estados que não cumprem com a lei do piso, contribuindo para manter o quadro de desvalorização dos professores no Brasil. (MASSON, 2016, p. 157).

Sobre o cenário referente ao cumprimento do piso nos estados brasileiros, Masson (2016, p. 165) afirma que

Os dados indicam que das 27 (vinte e sete) unidades federativas, 16 (dezesseis) cumpriam integralmente, em 2014, a Lei do Piso n 11.738, aprovada em 2008, representando somente $59 \%$ do total. Em relação ao estado que apresenta o melhor vencimento inicial (Mato Grosso do Sul) e o que possui o pior vencimento (Amapá) a diferença é de quase três vezes, ou seja, o menor vencimento corresponde a 34\% do maior.

De acordo com os dados da pesquisa realizada nos estados, eles apresentam realidades distintas devido ao desenvolvimento econômico, social e educacional de cada região a que pertencem, o que interfere nas condições de trabalho e remuneração docente.

Neste artigo, dedicamo-nos a sistematizar os dados da pesquisa sobre os municípios das mesorregiões Sudeste e Centro-Oriental do Paraná. Esse estado conta com 399 municípios, uma população de 10.444 .526 habitantes, numa área de 199.307,95 km2, com IDHM de 0,749, que o faz ocupar a $5^{a}$ posição entre as 27 unidades federativas brasileiras. Nesse ranking, o maior IDHM é 0,824, no Distrito Federal, e o menor é 0,631, em Alagoas (ATLAS BRASIL, 2010). Em 2010, 87,18\% da população de 6 a 17 anos do Paraná estava cursando o ensino básico regular com até dois anos de defasagem idade-série. Em 2000, eram 87,63\% e, em 1991, 80,60\%. A renda per capita média foi de $\mathrm{R} \$ 890,89$ em 2010 e a proporção de pessoas pobres, ou seja, com renda domiciliar per capita inferior a $\mathrm{R} \$ 140,00$ (a preços de agosto de 2010), foi de 6,46\% em 2010. (IPARDES, 2016).

Segundo dados do IPARDES (2016), o estado conta com 5.128 estabelecimentos de ensino (Regular, Especial e EJA) sob responsabilidade das redes municipais. Foram 336.613 matrículas nas redes municipais do estado, e 
687.572 matrículas no Ensino Fundamental. No que se refere às funções docentes nas Redes Municipais no ensino Regular, Especial e EJA, o estado conta com 61.464 docentes $^{2}$.

\section{ASPECTOS METODOLÓGICOS DA PESQUISA}

A pesquisa tratou de analisar a atratividade da carreira do magistério dos professores dos anos iniciais do Ensino Fundamental das mesorregiões Sudeste e Centro Oriental do Paraná, nas quais estão inseridas as universidades envolvidas no estudo, a saber: Universidade Estadual de Ponta Grossa e a Universidade Estadual do Centro Oeste.

O desenvolvimento das investigações ocorreu com a participação de dois grupos de pesquisa, incluindo os pesquisadores e estudantes de graduação, mestrado e doutorado, tendo como fontes principais os planos de carreira e tabelas salariais de vencimentos iniciais e finais atualizadas dos municípios contemplados na pesquisa.

O levantamento dos planos de carreira e tabelas salariais atualizadas dos professores exigiu maior tempo de pesquisa e a contribuição dos estudantes e professores dos dois grupos de pesquisa envolvidos, uma vez que tivemos dificuldades para acessar a legislação dos municípios, em virtude da não publicização de informações nos sites das instituições.

Os dados referentes aos planos de carreira e às tabelas salariais apresentados neste trabalho foram obtidos dos sites das prefeituras e câmaras municipais, assim como do portal da transparência, dos editais de concursos e de contatos via e-mail e telefone com a seção de recursos humanos das prefeituras.

Para o trabalho estatístico em relação aos vencimentos, realizamos análise de variância (ANOVA), buscando verificar se existem diferenças estatisticamente significativas entre as médias de vencimentos para os diferentes níveis dos fatores Mesorregião, Nível de Formação e Tempo de Carreira (Inicial x Final), considerando a densidade populacional (habitante por $\mathrm{km} 2$ ) como covariável.

Também foram realizados os Testes de comparação de médias HSD de Tuckey e LSD de Fisher para identificar quais médias são diferentes entre si, como complemento para a análise de variância.

2 Corresponde ao total de docentes no ensino regular, educação especial e EJA em efetiva regência de classe na data de referência do censo escolar, na rede municipal. O total de docentes por município diverge do total de docentes do estado à medida que se aumentam as desagregações da informação, pois um docente pode trabalhar em dois municípios ou mais, e em duas dependências administrativas ou mais. (IPARDES, 2017). 


\section{DADOS E CARACTERÍSTICAS DA REGIÃO DE REALIZAÇÃO DA PESQUISA}

Segundo classificação do IPARDES, as duas mesorregiões possuem sete microrregiões e 35 municípios, relacionados na Tabela 1. A mesorregião Sudeste do Paraná é formada por 21 municípios e dividida em quatro microrregiões, enquanto a Região Centro-Oriental é formada por 14 municípios e dividida em três microrregiões. As principais características das duas mesorregiões são apresentadas na Tabela 1: área territorial (2017), população estimada (2016), IDHM (2010) e PIB Per Capita (2014), a partir de consulta à página do IPARDES (2016), dados disponíveis no link perfil avançado dos municípios.

\section{Tabela 1 - Características das mesorregiões Sudeste e Centro-Oriental do Paraná}

\begin{tabular}{|c|c|c|c|c|}
\hline Mesorregião & Área territorial & $\begin{array}{c}\text { População } \\
\text { estimada }\end{array}$ & IDHM & PIB per capita \\
\hline Sudeste & 16.941 .469 & 432.613 & 0,793 & 23.131 \\
\hline Centro-Oriental & 11.937 .564 & 339.787 & 0,749 & 26.541 \\
\hline
\end{tabular}

Fonte: IPARDES, 2016, elaboração dos autores.

Nessa pesquisa, consideramos os dados contidos nas tabelas salariais sem adicionais, gratificações e complementações; essa escolha deveu-se à dificuldade de identificar com exatidão esses valores, pois demandaria um estudo a partir das folhas de pagamento dos professores, algo que poderemos realizar em pesquisa futura.

Os dados referentes aos vencimentos foram obtidos nos sites institucionais, contato telefônico ou e-mail com o setor de recursos humanos. Essa coleta de dados foi necessária, pois possibilitou trabalhar com os dados atualizados de 2016 e 2017. Não tivemos êxito na busca das tabelas dos municípios de Piraí do Sul e Jaguariaíva, da mesorregião Centro-Oriental e Ipiranga da mesorregião Sudeste.

Entendemos que o piso salarial não pode ser confundido com o vencimento, uma vez que este pode estar acima daquele, especialmente para os profissionais que possuem formação superior ao nível médio, exigido pela Lei $n^{\circ}$ 11.738. Esse mínimo, por vezes, como afirma Gil (2017), torna-se o teto.

Esse desvirtuamento se confirma na região desta pesquisa (ver Tabela 2), pois, dos 35 municípios contemplados nesta investigação, quatro municípios da mesorregião Sudeste não cumprem o mínimo estabelecido por lei; são 
eles: Antônio Olinto, General Carneiro, Paula Freitas e Rebouças. Os demais apresentam vencimentos conforme estipulado pela lei do piso, com algumas variações.

Nesta pesquisa, analisamos a atratividade para ingresso e permanência na carreira docente, a partir de dados de vencimento inicial e final (Tabelas 2 e 3 ) por nível de formação nos 35 municípios da região de abrangência, bem como visou-se a identificar possíveis efeitos de fatores como PIB Per Capita, Densidade Populacional e IDHM sobre os vencimentos.

\section{Tabela 2 - Vencimento inicial (R\$) dos professores das redes municipais das Regiões Sudeste e Centro-Oriental do Paraná (20h) - 2017}

\begin{tabular}{|c|c|c|c|c|c|c|c|}
\hline \multirow[b]{2}{*}{ Mesorregião } & \multirow[b]{2}{*}{ Município } & \multicolumn{4}{|c|}{ Nível de formação } & \multirow{2}{*}{$\begin{array}{c}\text { PIB } \\
\text { Per Capita } \\
\text { (ranking) }\end{array}$} & \multirow[b]{2}{*}{ IDHM } \\
\hline & & Médio & Superior & $\begin{array}{l}\text { Lato } \\
\text { Sensu }\end{array}$ & $\begin{array}{l}\text { Stricto } \\
\text { Sensu }\end{array}$ & & \\
\hline Sudoeste & 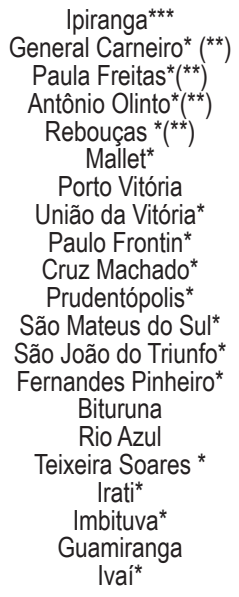 & $\begin{array}{l}100 \overline{1}, 16 \\
1008,38 \\
1032,87 \\
1057,89 \\
1067,82 \\
1067,82 \\
1067,82 \\
1069,06 \\
1071,67 \\
1072,13 \\
1075,30 \\
1149,40 \\
1150,31 \\
1228,25 \\
1245,50 \\
1270,00 \\
1278,22 \\
1318,48 \\
1358,99 \\
---\end{array}$ & $\begin{array}{l}1365,54 \\
1501,74 \\
1260,48 \\
1032,87 \\
1089,63 \\
1281,37 \\
1507,32 \\
1599,06 \\
1603,59 \\
1607,50 \\
1447,37 \\
1445,19 \\
1551,69 \\
1522,94 \\
1614,19 \\
1370,05 \\
1333,50 \\
1539,93 \\
1648,11 \\
1488,17 \\
1485,65\end{array}$ & $\begin{array}{l}-- \\
1652,22 \\
1512,58 \\
1209,89 \\
1121,37 \\
1537,66 \\
1784,07 \\
1846,91 \\
1763,95 \\
1821,30 \\
1592,10 \\
1661,97 \\
2094,78 \\
1667,97 \\
1775,65 \\
1465,95 \\
1397,00 \\
1654,03 \\
1714,02 \\
1590,11 \\
1659,21\end{array}$ & $\begin{array}{c}-- \\
- \\
-- \\
1330,89 \\
-- \\
1922,07 \\
-- \\
-- \\
-- \\
-- \\
-- \\
1911,28 \\
-- \\
-- \\
-- \\
1539,24 \\
-- \\
-- \\
1911,80 \\
-- \\
1890,62\end{array}$ & $\begin{array}{l}25838(17) \\
19353(27) \\
40635(3) \\
20774(25) \\
19591(26) \\
22661(20) \\
14372(34) \\
50035(2) \\
32848(9) \\
17362(29) \\
16732(31) \\
26085(15) \\
27177(14) \\
22250(22) \\
17417(28) \\
27900(13) \\
22488(21) \\
23688(19) \\
22082(23) \\
21625(24) \\
16293(32)\end{array}$ & $\begin{array}{l}-- \\
0,652 \\
0,717 \\
0,656 \\
0,672 \\
0,708 \\
0,685 \\
0,744 \\
0,708 \\
0,664 \\
0,676 \\
0,719 \\
0,629 \\
0,645 \\
0,667 \\
0,687 \\
0,671 \\
0,726 \\
0,660 \\
0,669 \\
0,651\end{array}$ \\
\hline $\begin{array}{l}\text { Centro- } \\
\text { Oriental }\end{array}$ & $\begin{array}{c}\text { Piraí do Sul(***) } \\
\text { Palmeira* } \\
\text { Arapoti* }^{*} \\
\text { Castro* }^{*} \\
\text { Tibagi* }^{*} \\
\text { Ventania* }^{*} \\
\text { Ponta Grossa* } \\
\text { Carambeí } \\
\text { Imbaú } \\
\text { Reserva } \\
\text { Ortigueira } \\
\text { Telêmaco Borba } \\
\text { Jaguariaíva*** } \\
\text { Sengés }\end{array}$ & $\begin{array}{l}-- \\
1064,20 \\
1067,82 \\
1067,82 \\
1067,82 \\
1067,82 \\
1095,25 \\
1149,40 \\
1149,40 \\
1149,40 \\
1149,66 \\
1260,01 \\
1376,15 \\
1436,75\end{array}$ & $\begin{array}{r}-- \\
1330,25 \\
1388,17 \\
1174,61 \\
1281,38 \\
1174,60 \\
1260,24 \\
1380,53 \\
1298,82 \\
1411,78 \\
1379,59 \\
1386,03 \\
-- \\
1738,47\end{array}$ & $\begin{array}{c}-- \\
1463,28 \\
1548,52 \\
1281,39 \\
1409,52 \\
1350,41 \\
1323,27 \\
1466,52 \\
1493,65 \\
1552,96 \\
1586,52 \\
1489,97 \\
-- \\
1768,25\end{array}$ & $\begin{array}{c}-- \\
1755,93 \\
-- \\
1388,18 \\
-- \\
-- \\
1455,60 \\
1906,47 \\
-- \\
2096,49 \\
-- \\
1564,51 \\
-- \\
--\end{array}$ & $\begin{array}{c}25851(16) \\
30687(11) \\
15618(33) \\
33293(8) \\
31932(10) \\
34348(7) \\
34670(6) \\
16763(30) \\
10824(35) \\
59105(1) \\
28650(12) \\
34907(5) \\
37401(4) \\
23712(18)\end{array}$ & $\begin{array}{l}--\overline{-} \\
0,711 \\
0,723 \\
0,703 \\
0,664 \\
0,650 \\
0,763 \\
0,728 \\
0,622 \\
0,618 \\
0,609 \\
0,734 \\
-- \\
0,663\end{array}$ \\
\hline
\end{tabular}

Fontes: Sites das prefeituras, Portal da Transparência, editais de concursos, dados das seções de recursos humanos dos municípios, organizados pelos autores (2017). Valores em Reais.

Obs.: Dados 2015 *; Dados de 2016 **, Dados 2017 ***: Municípios que não cumprem o piso salarial. Para a verificação do cumprimento da Lei do Piso Salarial (2008), tomamos como referência valores disponibilizados no site do Ministério da Educação, para 40h, a saber: 2015: R\$ 1.917,78; 2016: $\mathrm{R} \$ 2.135,64 ; 2017$ : R \$2.298,80. ***: Municípios que não informaram dados. 
No ranking em relação ao PIB per capita, os municípios que possuem os menores vencimentos ocupam a seguinte colocação (Tabela 4):

\section{Tabela 3 - Ranking de PIB dos municípios das Regiões Sudeste e Centro- Oriental do Paraná com menor vencimento inicial - 2017}

\begin{tabular}{|c|c|}
\hline Município & Colocação PIB - Mesorregião Sudeste e Centro-Oriental \\
\hline Paula Freitas & $3^{\circ}$ \\
\hline Antonio Olinto & $25^{\circ}$ \\
\hline Rebouças & $26^{\circ}$ \\
\hline General Carneiro & $27^{\circ}$ \\
\hline
\end{tabular}

Fonte: IPARDES, 2016, elaboração dos autores.

O município de Paula Freitas, no quadro dos 35 municípios das duas regiões, ocupa a terceira posição em relação ao PIB. Já General Carneiro, Antonio Olinto e Rebouças estão entre as últimas colocações. Buscamos não estabelecer comparações, pois entendemos que há muitas diferenças em relação à arrecadação de cada município, mas é possível observar que, mesmo com a Lei do Piso, numa mesma mesorregião existem diferenças no que se refere ao vencimento inicial.

Sobre os investimentos para a educação nesses municípios, no ano de 2015, segundo dados organizados pelo Datapedia (2015), temos os seguintes dados:

Tabela 4 - Investimentos na educação nas redes municipais das Regiões Sudeste e Centro-Oriental do Paraná com menores vencimentos - 2017

\begin{tabular}{|c|c|c|}
\hline Município & População & Investimento em Educação (R\$) \\
\hline Antonio Olinto & 7.582 & $4.645 .540,00$ \\
\hline Paula Freitas & 5.808 & $4.787 .800,00$ \\
\hline Rebouças & 14.926 & $9.020 .260,00$ \\
\hline General Carneiro & 14.038 & $9.276 .000,00$ \\
\hline
\end{tabular}

Fonte: Datapedia (2015); elaboração dos autores.

Antônio Olinto e Paula Freitas, dentre os municípios contemplados na pesquisa, ocupam as últimas colocações em relação aos investimentos na educação, mas as populações desses municípios também são menores. 
Em relação aos quatro maiores vencimentos iniciais temos: Ivaí, Sengés ${ }^{3}$, Jaguariaíva e Guamiranga, no ranking em relação ao PIB per capita das duas regiões, esses municípios possuem os maiores vencimentos e ocupam as posições conforme a Tabela 6:

Tabela 5 - Ranking de PIB das redes municipais das Regiões Sudeste e Centro-Oriental do Paraná com os quatro maiores vencimentos iniciais 2017

\begin{tabular}{|c|c|}
\hline Município & Colocação PIB - Mesorregião Sudeste e Centro-Oriental \\
\hline Jaguariaíva & $4^{\circ}$ \\
\hline Guamiranga & $12^{\circ}$ \\
\hline Sengés & $18^{\circ}$ \\
\hline Ivaí & $32^{\circ}$ \\
\hline
\end{tabular}

Fonte: IPARDES (2016), elaborada pelos autores.

Sobre a população e investimentos em educação no ano de 2015 (DATAPEDIA, 2015), nesses municípios com maiores vencimentos, temos os seguintes dados:

Tabela 6 - População e investimento em educação nas redes municipais das Regiões Sudeste e Centro-Oriental do Paraná com maiores vencimentos iniciais - 2017

\begin{tabular}{|c|c|c|}
\hline Município & População & Investimento em Educação (R\$) \\
\hline Ivaí & 13.714 & $7.854 .150,00$ \\
\hline Sengés & 19.373 & $11.129 .300,00$ \\
\hline Jaguariaíva & 34.647 & $18.381 .500,00$ \\
\hline Guamiranga & 8.552 & 5.695 .880 .00 \\
\hline
\end{tabular}

Fonte: Datapedia (2015), elaborada pelos autores.

O município de Ivaí não ocupa as primeiras colocações em relação ao PIB Per Capita; no entanto, possui vencimento inicial entre os quatro maiores nas duas mesorregiões. Observando-se o Plano de Carreira de Ivaí, a exigência mínima de formação para ingresso na carreira é o nível superior, com licenciatura plena em Pedagogia ou licenciatura plena acrescida do nível médio, modalidade normal, embora o município possua ainda professores com nível médio 
A análise dos maiores e dos menores vencimentos evidenciou que não há uma correspondência direta destes com o PIB per capita e o IDHM (Tabela 5, maior PIB para menor IDHM). Evidencia, também, a necessidade de fiscalização e possível complementação da união nas redes municipais que não cumprem o piso salarial $4^{4}$.

Segundo Azevedo (2017), 93 municípios do Paraná não seguem o piso salarial nacional para os professores previsto na Constituição Federal, de acordo com dados do Ministério Público de Contas do Paraná. Ainda, segundo notícia publicada no dia 19 de junho de 2017, no site Paraná Portal Notícias, “É papel do Ministério Público de Contas de cada estado incentivar que as administrações municipais busquem atingir as metas de ensino estipuladas pelo Ministério da Educação".

De acordo com os dados levantados na pesquisa, predomina o nível médio, modalidade normal, como formação mínima para ingresso na carreira docente na Educação Infantil e anos iniciais da Educação Básica.

Sobre a oferta e demanda de pedagogos no estado do Paraná, no período de 2009 a 2013, Vaz e Masson (2017, p. 1) revelam “que há uma oferta maior de pedagogos em relação ao crescimento da demanda de tais profissionais no mercado de trabalho, ocasionando uma população excedente de professores. A conclusão é de que esta condição contribui para a desvalorização do valor de sua força de trabalho".

Isso indica que muitos professores com nível superior, ao realizarem o concurso, cumprem o período de estágio probatório para, depois, enquadraremse no primeiro nível e/ou classe de formação superior.

Já existe jurisprudência em relação a isso no Tribunal de Justiça do Rio Grande do Sul, 5 "em que todos [os professores] passaram a ter inquestionável direito subjetivo a serem transferidos para o nível correspondente à titulação possuída na época, independentemente da existência de vaga, cuja existência

4 Quando os valores não são suficientes, os estados e municípios podem solicitar um complemento do Fundo de Manutenção e Desenvolvimento da Educação Básica e de Valorização dos Profissionais da Educação (Fundeb). Se, mesmo com o repasse do Fundeb, não for possível atingir o piso nacional obrigatório da categoria, previsto para chegar a 2.298,83 reais em 2017, o estado ou município pode solicitar a complementação do valor à União

5 Maiores informações sobre essa jurisprudência ver: https://tj-rs.jusbrasil.com.br/ jurisprudencia/113600015/apelacao-e-reexame-necessario-reex-70052194933-rs. 
era presumível, nem de qualquer outro requisito atinente a estágio probatório ou interstício mínimo." Isso também ocorreu em municípios do Rio Grande do Norte e Espírito Santo ${ }^{6}$.

É importante esclarecer a diferença entre estabilidade e efetividade, pois a primeira é a garantia constitucional de permanência no serviço púbico, outorgada à pessoa que foi nomeada em caráter efetivo, após ter ultrapassado o estágio probatório de três anos. A efetividade corresponde à situação de quem foi aprovado em concurso público, pressupondo uma situação de permanência na carreira. Sendo assim, todo profissional efetivo tem direito a receber um vencimento de acordo com a formação, embora não possa sair do primeiro nível do plano de carreira, até que finde o estágio probatório.

A seguir, tratamos dos dados sobre o vencimento final nas redes municipais analisadas, o qual corresponde ao último nível ou referência previsto na tabela salarial, sem vantagens pecuniárias, gratificações e outros adicionais. Para podermos ter um parâmetro de análise sobre a atratividade para a permanência na carreira, levantamos dados referentes aos vencimentos finais para os professores com nível médio, superior, pós-graduação lato sensu e stricto sensu. Observouse, no estudo, que o tempo para se chegar ao vencimento final apresenta muitas variações, pois o docente pode ingressar com pós-graduação ou até mesmo se manter com nível médio durante toda a carreira.

\section{Tabela 7 - Vencimento final ( $R \$)$ dos professores das redes municipais das Regiões Sudeste e Centro Oriental do Paraná (20h) - 2017}

\begin{tabular}{|c|c|c|c|c|}
\hline Município & Nível Médio & Nível Superior & $\begin{array}{c}\text { Pós-graduação } \\
\text { lato sensu }\end{array}$ & $\begin{array}{c}\text { Mestrado e } \\
\text { Doutorado }\end{array}$ \\
\hline Ipiranga & --- & --- & --- & -- \\
\hline Jaguariaíva & --- & -- & --- & -- \\
\hline Piraí do sul & --- & --- & --- & -- \\
\hline Antônio Olinto & $1.096,49$ & $1.151,30$ & $1.674,78$ & $1.842,23$ \\
\hline Paula Freitas & $1.323,09$ & $1.653,86$ & $1.984,63$ & -- \\
\hline Ventania & $1.327,70$ & $1.460,47$ & $1.679,54$ & $1.931,47$ \\
\hline General Carneiro & $1.345,47$ & $2.018,20$ & $2.220,40$ & -- \\
\hline São Mateus do Sul & $1.418,83$ & $1.906,89$ & $2.192,97$ & $2.521,92$ \\
\hline Cruz Machado & $1.440,23$ & $2.160,35$ & $2.376,37$ & -- \\
\hline
\end{tabular}

6 Aracruz - Espírito Santo: https://tj-es.jusbrasil.com.br/jurisprudencia/17819489/remessa-exofficio-6080042614-es-006080042614-tjes/decisao-monocratica-17819490.

Rio Grande do Norte: https://tj-rn.jusbrasil.com.br/jurisprudencia/5708253/apelacao-civel-ac-99180rn-2008009918-0/inteiro-teor-11868723?ref=juris-tabs. 
Tabela 7 - Vencimento final (R\$) dos professores das redes municipais das Regiões Sudeste e Centro Oriental do Paraná (20h) - 2017

\begin{tabular}{|c|c|c|c|c|}
\hline Município & Nível Médio & Nível Superior & $\begin{array}{l}\text { Pós-graduação } \\
\text { lato sensu }\end{array}$ & $\begin{array}{l}\text { Mestrado e } \\
\text { Doutorado }\end{array}$ \\
\hline Ipiranga & -- & -- & -- & -- \\
\hline Jaguariaíva & --- & --- & --- & -- \\
\hline Piraí do sul & --- & --- & --- & --- \\
\hline Antônio Olinto & $1.096,49$ & $1.151,30$ & $1.674,78$ & $1.842,23$ \\
\hline Paula Freitas & $1.323,09$ & $1.653,86$ & $1.984,63$ & -- \\
\hline Ventania & $1.327,70$ & $1.460,47$ & $1.679,54$ & $1.931,47$ \\
\hline General Carneiro & $1.345,47$ & $2.018,20$ & $2.220,40$ & -- \\
\hline São Mateus do Sul & $1.418,83$ & $1.906,89$ & $2.192,97$ & $2.521,92$ \\
\hline Cruz Machado & $1.440,23$ & $2.160,35$ & $2.376,37$ & --- \\
\hline Mallet & $1.455,32$ & $1.823,30$ & $2.188,56$ & $2.735,7$ \\
\hline Fernandes Pinheiro & $1.472,41$ & $1.987,75$ & $2.134,99$ & -- \\
\hline Arapoti & $1.478,11$ & $1.921,55$ & $2.143,26$ & -- \\
\hline Prudentópolis & $1.484,08$ & $2.003,50$ & $2.203,84$ & -- \\
\hline Tibagi & $1.509,15$ & $1.810,98$ & $1.992,07$ & -- \\
\hline Rio Azul & $1.548,62$ & $1.703,48$ & $1.822,73$ & $1.913,87$ \\
\hline Teixeira Soares & $1.564,33$ & $1.642,30$ & $1.720,76$ & --- \\
\hline Telêmaco Borba & $1.573,57$ & $1.730,92$ & $1.860,76$ & $1.953,82$ \\
\hline Irati & $1.578,95$ & 2131,62 & $2.289,58$ & -- \\
\hline Reserva & $1.581,82$ & $2.135,45$ & $2.348,99$ & $3.171,13$ \\
\hline Rebouças & $1.600,15$ & $1.648,16$ & $1.696,17$ & -- \\
\hline Porto Vitória & $1.663,61$ & $2.348,36$ & $2.779,51$ & -- \\
\hline Imbituva & $1.674,47$ & $2.093,10$ & $2.176,81$ & $2.427,99$ \\
\hline Carambeí & $1.738,57$ & $2.088,17$ & $2.218,25$ & $2.883,71$ \\
\hline Ortigueira & $1.738,96$ & $2.086,75$ & $2.399,76$ & --- \\
\hline Bituruna & $1.803,70$ & $2.370,55$ & $2.607,62$ & -- \\
\hline Ivaí & $1.847,22$ & $2.093,10$ & $2.176,81$ & $2.427,99$ \\
\hline União da Vitória & $1.923,08$ & $2.879,82$ & $3.326,19$ & -- \\
\hline Paulo Frontin & $1.930,84$ & $2.896,26$ & $3.185,89$ & -- \\
\hline Imbaú & $1.965,79$ & $2.221,34$ & $2.554,54$ & -- \\
\hline Guamiranga & $1.970,54$ & $2.143,88$ & $2.157,85$ & $2.305,66$ \\
\hline São João do Triunfo & $1.979,00$ & -- & -- & -- \\
\hline Palmeira & $2.053,91$ & $2.567,38$ & $2.824,12$ & $3.388,94$ \\
\hline Sengés & $2.255,70$ & $3.333,26$ & $3.936,70$ & --- \\
\hline Ponta Grossa & $2.655,35$ & $3.055,34$ & $3.208,90$ & $3.528,90$ \\
\hline Castro & $2.680,20$ & $2.948,24$ & $3.126,26$ & $3.484,30$ \\
\hline
\end{tabular}

Fonte: Tabelas salariais dos municípios; elaboração dos autores. 
Os dados evidenciam que os maiores vencimentos para quem possui a formação em nível médio são das seguintes redes municipais: Castro, Ponta Grossa, Sengés e Palmeira. No entanto, vale destacar que na rede municipal de Ponta Grossa, segundo o Art. 13, da Lei no 12.269, de 2015, cada nível é composto de trinta referências, com valores de vencimentos acrescidos de um por cento de uma referência para outra. Neste caso, no avanço horizontal, segundo art. 90 do Plano de Carreira de Ponta Grossa, observar-se-á o interstício de 2 anos, podendo-se avançar até duas referências mediante critérios mínimos de avaliação de desempenho. Mesmo considerando que é possível a progressão até duas referências, ainda assim o professor não terá possibilidade de chegar à última referência da tabela, uma vez que a sua provável aposentadoria acontece após 25 anos de trabalho para alcançar o último nível.

Os dados também indicam que somente 15 municípios têm planos que contemplam o nível e/ou classe com mestrado e doutorado; os demais finalizam na especialização lato sensu. Vale destacar, também, as dificuldades para os professores cursarem pós-graduação, muitas vezes sem afastamento e apoio financeiro.

\section{RESULTADOS E DISCUSSÕES}

O estudo da atratividade da carreira de professores se justifica por se tratar de cargo público e sujeito a definições políticas, de disponibilidade de recursos, entre outras questões. Vencimentos médios (em reais) no início da carreira e no final das ascensões do professor são apresentados na Tabela 8 para as mesorregiões Sudeste e Centro-Oriental do Paraná. Como já destacamos, não conseguimos ter acesso às tabelas de Piraí do Sul, Jaguariaíva e Ipiranga, razão pela qual não foram apresentados, na tabela anterior, dados referentes ao vencimento final.

\section{Tabela 8 - Vencimentos médios $(\mathbf{R} \$)$ por níveis de formação e ascensões para as Mesorregiões Sudeste e Centro-Oriental do Paraná -2017}

\begin{tabular}{|c|c|c|c|c|c|}
\hline Carreira & Mesorregião & Médio & Superior & Especialização & $\begin{array}{c}\text { Mestrado e } \\
\text { Doutorado }\end{array}$ \\
\hline \multirow{2}{*}{ Inicial } & Centro-Oriental & $1.160,78$ & $1.369,84$ & $1.501,71$ & $1.655,79$ \\
& Sudeste & $1.205,05$ & $1.520,85$ & $1.702,63$ & $1.768,21$ \\
\hline \multirow{2}{*}{ Final } & Centro-Oriental & $1.916,83$ & $2.312,06$ & $2.554,15$ & $2.819,96$ \\
& Sudeste & $1.648,05$ & $2.122,83$ & $2.388,13$ & $2.475,88$ \\
\hline
\end{tabular}

Fonte: Dados das tabelas salariais; elaboração dos autores. 
Considerando que ocorrem para o início de carreira vencimentos médios ligeiramente superiores para a mesorregião Sudeste em relação à Centro-Oriental ocorrendo o contrário para o final de carreira, apresentamos na Tabela 9 os cálculos de percentuais das diferenças entre os vencimentos das mesorregiões.

Calculamos também os tempos em termos de percentual de carreira para a igualdade, ou seja, para a mesorregião Centro-Oriental apresentar vencimentos iguais aos da Sudeste. Por exemplo, para o nível médio a igualdade ocorre quando decorrido 18,94\%, ou seja, com aproximadamente quatro anos e nove meses de uma carreira de 25 anos.

Tabela 9 - Diferenças Percentuais nos vencimentos médios iniciais e finais entre as Mesorregiões Sudeste e Centro-Oriental do Paraná e tempo para igualdade -2017

\begin{tabular}{|c|c|c|c|c|c|}
\hline Mesorregião com vencimento superior & Médio & Superior & Especialização & $\begin{array}{c}\text { Mestrado e } \\
\text { Doutorado }\end{array}$ & Média \\
\hline Sudeste (Início de carreira) & $3,81 \%$ & $11,02 \%$ & $13,38 \%$ & $6,79 \%$ & $8,75 \%$ \\
\hline Centro-Oriental (Final de carreira) & $16,31 \%$ & $8,91 \%$ & $6,95 \%$ & $13,90 \%$ & $11,52 \%$ \\
\hline Tempo de carreira para igualdade & $18,94 \%$ & $55,29 \%$ & $65,81 \%$ & $32,82 \%$ & $43,17 \%$ \\
\hline
\end{tabular}

Fonte: Dados das tabelas salariais; elaborada pelos autores.

O Gráfico 1 apresenta mais detalhadamente a dispersão de valores por município, que origina as médias e diferenças de vencimento entre as duas mesorregiões paranaenses pesquisadas. 
Gráfico 1 - Médias ${ }^{7}$, medianas ${ }^{8}$ e intervalos de dispersão ${ }^{9}$ para Vencimentos entre os municípios das Mesorregiões Sudeste e CentroOriental do Paraná - 2017

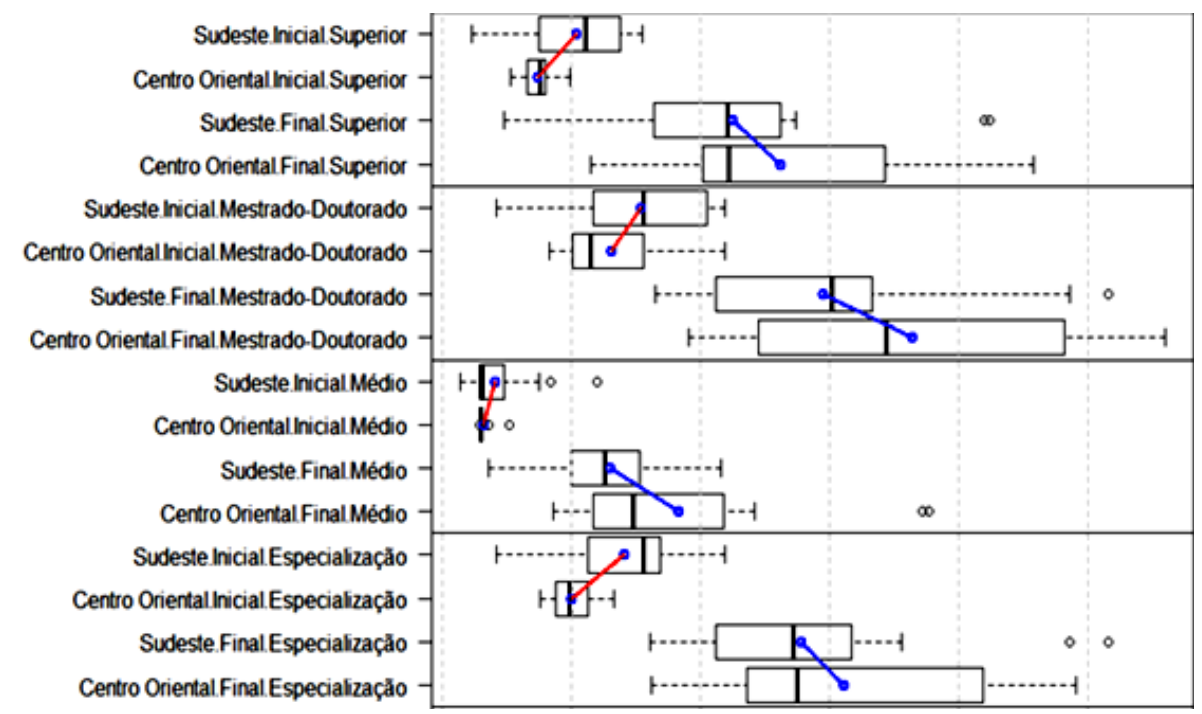

Fonte: Tabelas salariais; elaboração dos autores.

A característica de alternância entre superioridade de vencimentos inicial para a mesorregião Sudeste e final para a mesorregião Centro-Oriental é destacada com segmentos de reta em vermelho e em azul, respectivamente, entre os valores médios de vencimentos em cada nível de formação e mesorregião. Tal característica deve indicar a significância da interação entre os fatores mesorregião e nível de formação na Análise de Variâncias (ANOVA).

Para os vencimentos iniciais ocorrem menores variações (dispersão) entre os municípios das duas mesorregiões; para vencimentos finais, as dispersões e diferenças são aparentemente maiores.

Para identificar se as médias de vencimentos entre os diferentes níveis dos fatores Mesorregião, Nível de Formação e Tempo de Carreira apresentam diferenças estatisticamente significativas, procedeu-se ao teste da ANOVA, considerando a covariável densidade populacional (habitante por $\mathrm{km} 2$ ) conforme a Tabela 10.

\footnotetext{
$7 \quad$ Pontos em Azul

$8 \quad$ Traço em negrito dentro das caixas

$950 \%$ da dispersão dentro das caixas e $25 \%$ em cada bigode
} 
Tabela 10 - ANOVA para Vencimentos por Fatores (Mesorregião, Nível de Formação e Tempo do Vencimento) e Covariável Densidade Populacional das Mesorregiões Sudeste e Centro-Oriental do Paraná - 2017

\begin{tabular}{|c|c|c|c|c|c|}
\hline Fonte de Variação & G. L. & $\begin{array}{c}\text { Soma de } \\
\text { Quadrados }\end{array}$ & $\begin{array}{c}\text { Quadrado } \\
\text { Médio }\end{array}$ & $\mathbf{F}$ & $\operatorname{Pr}(>\mathbf{F})$ \\
\hline Densidade Populacional & 1 & $1,648 \mathrm{E}-06$ & $1,648 \mathrm{E}-06$ & 13,702 & $0,03 \%$ \\
\hline Mesorregião & 1 & $4,430 \mathrm{E}-08$ & $4,430 \mathrm{E}-08$ & 0,368 & $54,45 \%$ \\
\hline Nivel de Formação & 3 & $3,244 \mathrm{E}-05$ & $1,081 \mathrm{E}-05$ & 89,874 & $0,00 \%$ \\
\hline Tempo de Carreira & 1 & $5,239 \mathrm{E}-05$ & $5,239 \mathrm{E}-05$ & 435,479 & $0,00 \%$ \\
\hline Mesorregião: Tempo do Carreira & 1 & $2,242 \mathrm{E}-06$ & $2,242 \mathrm{E}-06$ & 18,641 & $0,00 \%$ \\
\hline Resíduos & 248 & $2,983 \mathrm{E}-05$ & $1,203 \mathrm{E}-07$ & & \\
\hline
\end{tabular}

Dados transformados: Box-Cox $\square=-0,80808$ ). Resíduos normais (Anderson Darling: P = 69\%); Variâncias homogêneas (Fligner-Killeen: $\mathrm{P}=16,2 \%$ ).

O teste da Análise de Variância (ANOVA) indica que existem diferenças estatisticamente significativas entre as médias dos vencimentos para os fatores Nível de Formação (valor $\mathrm{p}=0,00 \%$ ), fator Tempo de Carreira (Inicial x Final) (valor $\mathrm{p}=0,00 \%$ ), bem como para as interações entre fatores Mesorregião: Tempo de Carreira (valor-p $=0,00 \%$ ) e para a covariável Densidade Populacional (valor-p $=0,03 \%)$.

A covariável PIB Per Capita, enquanto potencial indicador de maior disponibilidade de recursos, não apresentou efeito estatisticamente significativo sobre as médias de vencimentos; da mesma forma, a covariável IDHM, sendo ambas retiradas da análise.

O fator Mesorregião, mesmo sem efeito estatisticamente significativo sobre as médias de vencimentos, foi mantido na análise por apresentar interação estatisticamente significativa com o fator Nível de formação.

Embora, para o fator Mesorregião, as diferenças em vencimentos não tenham apresentado significância estatística (valor-p $=54,45 \%$ ), isto pode ser resultado da alternância de valorizações entre os diferentes planos de carreira das duas mesorregiões.

O fator Tempo de Carreira apresenta valorização de vencimentos mais lenta ao longo do tempo para a mesorregião Sudeste, embora, nesta, os vencimentos iniciais médios sejam maiores, explicando a alternância verificada.

A significância da interação entre Mesorregião e Tempo de Carreira (Tabela 11, valor $\mathrm{p}=0,00 \%$ ) reflete a condição observada nas Tabelas 9 e 10, em que a Mesorregião Sudeste apresenta vencimentos superiores aos da Mesorregião 
Centro-Oriental para o Tempo de Carreira Inicial, condição que se inverte para o Tempo de Carreira Final, com tempo médio para igualdade em torno de 43\% da carreira.

O teste HSD de Tukey indica que as diferenças entre os vencimentos são estatisticamente significativas (valor-p $=0,00 \%$ ) entre todos os níveis do fator Nível de Formação, exceto entre o nível Especialização e Mestrado-Doutorado, com valor $\mathrm{p}=19,82 \%$; isso relaciona-se ao fato de que poucos municípios têm em seus planos de carreira a previsão de remuneração adicional para a pós-graduação Stricto Sensu.

Para o fator Tempo de Carreira, o teste HSD de Tukey indicou, com valor $\mathrm{p}=0,00 \%$, que a diferença entre as médias da variável vencimento é estatisticamente significativa entre os níveis Inicial e Final, como esperado e que espelha as diferenciações de vencimentos ao longo da carreira, correspondentes aos planos de carreira.

O Teste LSD de Fisher, com correção de Bonferroni para eventuais problemas com desbalanceamento (número diferente de observações por grupo), corrobora o teste de Tukey, apontando os mesmos resultados.

Embora os testes de Tukey e de Fisher tenham indicado que as diferenças entre vencimentos não sejam estatisticamente significativas para os níveis Especialização e Mestrado-Doutorado, essa indicação pode ser devida à maior dispersão de vencimentos pela não remuneração adicional por alguns municípios. Dessa forma, pode-se destacar o percentual adicional médio para MestradoDoutorado em relação à Especialização que é de 10,41\%, na Mesorregião CentroOriental e de 3,67\% na Mesorregião Sudeste.

\section{CONSIDERAÇÕES FINAIS}

Considerando que os estudos já realizados apontam uma disparidade nas carreiras docentes, tanto nas redes estaduais como nas municipais, buscamos identificar essas diferenças nos municípios contemplados na investigação, tendo como foco central a análise da atratividade no ingresso e permanência na carreira do magistério, a partir da verificação do vencimento inicial e final dos professores. Entre os vencimentos iniciais das duas regiões, as diferenças não aparentam ser significativas; no entanto, as diferenças entre os vencimentos ao final das ascensões são expressivas. A Região Sudeste apresenta maiores médias iniciais que a CentroOriental; todavia, ocorre o contrário para o final de ascensões.

Podemos afirmar que, no conjunto dos 35 planos de carreira analisados, ainda há muito que avançar em relação à valorização docente: são muitos os desafios e lutas por parte dos professores das redes municipais que, na nossa 
concepção, estão em situação inferior aos professores das redes estaduais, que também enfrentam lutas constantes pela manutenção dos direitos, como é caso do Estado do Paraná.

No que se refere ao requisito 'remuneração proporcional à formação com equiparação às demais profissões de formação equivalente', ao se considerar o vencimento inicial com formação de nível superior nos 35 municípios, temos valores entre $R \$ 1.032,87$ (menor) a $R \$ 1.738,47$ (maior).

Segundo pesquisa publicada em junho de 2017, no site G1 notícias, "na rede municipal, onde atua metade dos professores, a média de remuneração é de 4,3 salários mínimos.” (MORENO, 2017, s/p). No caso do estado do Paraná, o salário mínimo, em 2017, foi de $\mathrm{R} \$ 1.223,20$. Nesse sentido, por meio da pesquisa realizada, identificamos que o maior vencimento inicial das duas regiões de um professor da rede municipal com nível superior para 20 horas de trabalho, é de $\mathrm{R} \$ 1.738,47$, o que equivale a menos de 1,5 do salário mínimo do Paraná. Se considerarmos 40 horas, teremos um valor de $\mathrm{R} \$ 3.476,94$, ou seja, três salários, resultado diferente da média nacional de 4,3 salários, conforme apontado anteriormente. $\mathrm{O}$ menor vencimento nos 35 municípios é $\mathrm{R} \$ 2.065,74$ para 40 horas, para professor com nível superior, o que não corresponde a dois salários mínimos do Paraná.

Após a conclusão da pesquisa, buscaremos mobilizar os sindicatos dos professores dos 35 municípios para que tenham acesso aos dados e possam instrumentalizar e qualificar as lutas dos docentes em defesa da valorização.

Além disso, observamos a necessidade de continuar a pesquisa a partir dos elementos identificados nesta investigação que poderão compor outras problemáticas para pesquisas futuras vinculadas aos dois grupos de pesquisa (PPGE/UNICENTRO e PPGE/UPEG).

\section{REFERÊNCIAS}

ATLAS BRASIL. Atlas do Desenvolvimento Humano no Brasil. 2010. Disponível em: http://atlasbrasil.org.br/2013/. Acesso junho de 2017.

AZEVEDO, Francielly. 93 municípios do Paraná não seguem o piso salarial nacional para os professores. Paraná Portal de Notícias. 19 de junho de 2017. Disponível em: https://paranaportal.uol.com.br/cidades/93-municipios-doparana-nao-seguem-o-piso-salarial-nacional-para-os-professores/. Acesso em: agosto de 2017. 
BRASIL. Lei no 11.738, de 16 de julho de 2008. Regulamenta a alínea “e” do Inciso III do caput do art. 60 do Ato das Disposições Constitucionais Transitórias, para instituir o piso salarial profissional nacional para os profissionais do magistério público da educação básica. Diário Oficial da União, Brasília, 2008. Disponível em: <http://www.planalto.gov.br/ccivil_03/_ato2007-2010/2008/lei/111738. htm >. Acesso em: 3 abr. 2016.

BRASIL. Lei 8112, de 11 de dezembro de 1990. Dispõe sobre o regime jurídico dos servidores públicos civis da União, das autarquias e das fundações públicas federais. Brasília: Senado Federal, 1990. Disponível em: <http:// www.planalto.gov.br/ccivil_03/leis/L8112cons.htm>Acesso em: maio 2017.

BRASIL. Constituição da República Federativa do Brasil de 1988. Brasília: Senado Federal, 1988. Disponível em: <http://www.planalto.gov.br/ccivil_03/ constituicao/constituicaocompilado >. Acesso em: 7 dez. 2015

CAMARGO, R.B. et al. Financiamento da educação e remuneração docente: um começo de conversa em tempos de piso salarial. Revista Brasileira de Política e Administração da Educação RBPAE. v. 25, n. 2, p. 341-363, mai. /ago. 2009. Disponível em: <file://C:/Users/User/Downloads/19501-70750-1-PB\%20 (2).pdf>. Acesso em: 13 jan. 2016.

DATAPEDIA. 2015. Disponível em: https://www.datapedia.info/mapa. Acesso em: junho de 2017.

GIL, Juca. Comunicação mesa redonda do XXVIII Simpósio Brasileiro de Política e Administração da Educação, 26 a 28/04/2017, Universidade Federal da Paraíba (UFPB) - João Pessoa-PB, Anais...

IPARDES. Base de Dados do Estado-BDEweb. Disponível em: <http:// www.ipardes.pr.gov.br/imp/index.php>. Acesso: dia junho 2017.

IPARDES. Perfil avançado dos municípios. Disponível em: http://www. ipardes.gov.br/index.php?pg_conteudo $=1 \&$ cod_conteudo $=29$.

Acesso: setembro de 2016.

MASSON, G. A valorização dos professores e a educação básica nos estados. Revista Retratos da Escola, Brasília, v. 10, n. 18, p. 157-174, jan. /jun. 2016. Disponível em: <http//www.esforce.org.br>. Acesso em: 15 jun. 2017. 


\section{MORENO, A.C. $\mathbf{9 9 \%}$ dos professores brasileiros ganham em média menos}

de R\$ 3,5 mil, diz estudo. 22/06/2017 G1. https://g1.globo.com/educacao/ noticia/99-dos-professores-brasileiros-ganham-menos-de-r-35-mil-diz-estudo. ghtml. Disponível em: Acesso: julho de 2017.

\section{PONTA GROSSA. Lei no 12.269/2015. Plano de Empregos, Carreira e remuneração do Magistério Público Municipal de Ponta Grossa (PR). Ponta Grossa: Câmara Municipal de Ponta Grossa, 2015.}

VAZ, M. R. T; MASSON, G. A (des) valorização profissional docente: implicações da oferta e demanda de pedagogos no Paraná (2009-2013). Práxis Educativa, Ponta Grossa, v. 12, n. 1, p. 223-243, jan. / abr. 2017 Disponível em: < http:/ /www. revistas2.uepg.br/index.php/praxiseducativa/article/view/9503/0>. Acesso em: 2 maio 2017.

MICHELLE FERNANDES LIMA é professora da Universidade Estadual do Centro Oeste: Campus Irati ( PR), nas disciplinas de Metodologia da Pesquisa em Ciências da Educação e Politicas Educacionais. Professora do Programa de Pós Graduação em Educação. Mestre em fundamentos da educação pela Universidade Estadual de Maringá. Doutora em educação pelo Programa de Pós Graduação em Educação da UFPR. Pós Doutorado pela Universidade Estadual de Ponta Grossa (PPGE/UEPG). Professora do Programa de Pós Graduação em Educação da Universidade Estadual do Centro Oeste. Líder do grupo de pesquisa Estado, Politicas e Gestão da Educação (UNICENTRO/IRATIPR), Pesquiso nas linhas: Formulação, implementação e avaliação das políticas educacionais (Ed. Básica e Superior); Pesquisa em Politicas Educacionais; Política educacional em Gramsci; História da política educacional (educação superior). E-mail: mfernandeslima@yahoo.com.br

GISELE MASSON é doutora em Educação pela Universidade Federal de Santa Catarina, Mestre em Educação pela Universidade Estadual de Ponta Grossa e Licenciada em Pedagogia pela mesma universidade (1996). É professora do Departamento de Educação e do Programa de Pós-Graduação em Educação da Universidade Estadual de Ponta Grossa. Coordena o Grupo de Pesquisa Capital, Trabalho, Estado, Educação e Políticas Educacionais. Atuou como vicecoordenadora no Programa de Pós-Graduação em Educação da Universidade Estadual de Ponta Grossa no período de 2012 a 2014. Fez parte da diretoria do Sindicato dos Docentes da Universidade Estadual de Ponta Grossa (SINDUEPGANDES) no período de 2010 a 2012 e de 2014 a 2016 . É membro da Associação Nacional pela Formação dos Profissionais da Educação (ANFOPE) e do Conselho Acadêmico da Red de Estudios Teóricos y Epistemológicos en Política Educativa (RELEPE). Integra a Rede de Pesquisadores sobre Associativismo e Sindicalismo dos Trabalhadores em Educação (REDE ASTE). E-mail: gimasson@uol.com.br 
ARTUR LOURIVAL DA FONSECA MACHADO possui graduação em Matemática pela Fundação Faculdade Estadual de Filosofia Ciências e Letras de Guarapuava (1988), mestrado em Métodos Numéricos em Engenharia pela Universidade Federal do Paraná (2001) e doutorado em Engenharia Florestal pela Universidade Federal do Paraná (2009). Atualmente é professor adjunto da Universidade Estadual do Centro-Oeste. Tem experiência na área de Matemática, com ênfase em Pesquisa Operacional, atuando principalmente com os seguintes temas: Pesquisa Operacional, Matemática Aplicada, Dendrometria, Ensino Superior e Estatística. E-mail: arturlfm@gmail.com

Recebido em março de 2018 Aprovado em novembro de 2018 